\title{
Human epididymis protein 4 may not be a reliable screening biomarker for detecting lung carcinoma patients
}

\author{
BETUL CELIK and TANGUL BULUT \\ Department of Pathology, University of Health Sciences, Antalya Training and Research Hospital, Antalya 07050, Turkey
}

Received July 27, 2017; Accepted August 8, 2017

DOI: $10.3892 /$ br.2017.971

\begin{abstract}
Human epididymis protein 4 (HE4) acts as a protease inhibitor. It has been detected in the serum of patients with lung cancer patients and its utility for lung cancer screening was found in different studies. Nevertheless, little is known regarding the expression of HE4 in lung carcinoma subtypes. The aim of the present study was to investigate whether HE4 expression is a reliable marker for detecting any lung carcinoma subtypes, including small cell lung cancer (SCLC), non-small cell lung cancer (NSCLC) and adenocarcinoma (AC). In total, 141 lung carcinoma patients were enrolled in the study. Biopsy samples were obtained from bronchoscopic biopsy. The tumors were classified as SCLC (group 1, 54 cases) or NSCLC (group 2, 87 cases) based on histology and immunohistochemistry. The latter was sub-grouped as adenocarcinoma (group 2a, $\mathrm{AC}$ ) and squamous cell carcinoma (group 2b, SCC). The immunohistochemical expression of HE4 was compared between the groups. The study revealed that the majority of the SCLC and SCC cases were devoid of HE4 (90.1 and $89.65 \%$, respectively). Approximately $10 \%$ of cases had HE4 immune expression and the staining was focal and moderate throughout the tumor tissue. On the other hand, $78.8 \%$ of AC expressed HE4 and the staining was diffuse and strong. The overall HE4 expression in the lung cancer patients was $33.7 \%$. In conclusion, the results of the present study have shown that HE4 is expressed in adenocarcinoma of the lung but it is not frequent in SCC and SCLC. The value of HE4 as
\end{abstract}

Correspondence to: Dr Betul Celik, Department of Pathology, University of Health Sciences, Antalya Training and Research Hospital, Defterdarlik Bulvari, Antalya 07050, Turkey

E-mail: bet_celik@yahoo.com

Abbreviations: HE4, human epididymis protein 4; WFDC, whey acidic protein four-disulfide core; PCNA, proliferating cell nuclear antigen; TTF-1, thyroid transcription factor-1; HMWK, high molecular weight; IHC, immunohistochemistry; PBS, phosphate-buffered solution; DAB, 3,3'-diaminobenzidine; AUC, the area under the ROC curve

Key words: human epididymis protein 4, lung, small cell, adenocarcinoma, squamous cell a screening biomarker for lung cancer is limited but its presence exclusively in adenocarcinoma may provide new insight for targeted therapy.

\section{Introduction}

Human epididymis protein 4 (HE4) is a secretory protein originally found in epididymis (1). It has 124-amino acid long polypeptide that has two whey acidic protein four-disulfide core (WFDC) domains (2). The recombinant HE4 protein is shown to exhibit proteinase inhibitory activity towards trypsin, elastase, and matrix metallopeptidase 9 (3). Extracellular HE4 protein is able to increase DNA synthesis, and modulates mRNA and protein levels of cell cycle marker proliferating cell nuclear antigen (PCNA) and cell cycle inhibitor p21. The HE4-overexpressing ovarian cancer cell line promotes cell adhesion and migration and this ability is inhibited by HE4 suppression (4).

HE4 was first detected in the epididymis but it is not exclusive to epididymis. It is detected in the serum of patients with ovarian cancer and its utility for ovarian cancer monitoring was approved by the Food and Drug Administration in the United States. It is also involved in the innate immunity defense of the respiratory tract and nasal cavity (5). The level of HE4 is significantly elevated in malignant pleural effusions compared to non-malignant effusions (6). Its sensitivity (43.8-69.4\%) and specificity (78.5-95.0\%) for lung cancer detection $(6,7,8)$ has been previously identified and its increase in the serum after postoperative period was found to correlate with recurrence (9). Its serum concentration is also associated with tumor stage, and disease progression occurred within the first year in patients with small-cell lung cancer (SCLC) (10). Among locally advanced non-small cell lung cancer (NSCLC) patients, a higher serum level of HE4 has been found to predict non-responders to chemoradiotherapy (11). Moreover, HE4 expression had a 2-fold decrease in the 5-year disease-free survival compared to that in the negative expression group (12).

Based on previous studies, we determined whether HE4 is also expressed in tumor tissue or whether it is a secreted protein that is present only in the serum or body fluids. Furthermore, we assessed whether the prediction of its utility in lung cancer detection is applicable for all types of lung cancer including adeno (AC), squamous (SCC) and small cell (SCLC) carcinomas. 


\section{Materials and methods}

Following the approval by the Ethics Committee for Clinical Research of Akdeniz University, (25/11/2015-335), we retrospectively extracted 54 SCLC and 87 NSCLC cases from the archive of Department of Pathology, University of Health Sciences, Antalya Training and Research Hospital. Exclusion criteria were tumors with $<10$ tumor cells, or tumors from metastatic focuses. We included all the samples obtained with bronchoscopic biopsy from 2008 up to 2016, the time we started the study. For each case, a representative block containing sufficient tumor tissue was chosen. For subtyping of tumors, CD56 (clone 123C3; Genemed, San Francisco, CA, USA) and/or synaptophysin (clone SP11), chromogranin (clone SP12) (both from Thermo Fisher Scientific, Leicestershire, UK), thyroid transcription factor-1 (TTF-1, clone SPT24), CK7 (clone OV-TL 12/30), p63 (clone 7JUL) (all from Novocastra, Newcastle, UK), high molecular weight keratin (HMWK, cat. no. MS-1447-RQ; Thermo Fisher Scientific) and/or CK5/6 (clone D5/16 B4; cat. no. Mob362; Diagnostic BioSystems, Pleasanton, CA, USA) immunostaining, were applied immunohistochemically. HE4 immunostaining was applied manually, whereas a Leica Bond-Max automated immunohistochemistry (IHC) stainer was used for any other staining.

Tissue sections of normal human epididymis processed in a comparable manner provided a positive control. Negative controls were obtained by omitting the primary antibody. Cytoplasmic staining was graded for intensity ( 0 , negative; 1 , weak; 2, moderate; and 3, strong) and percentage of positive cells [0 (0\%), $1(1-24 \%), 2(25-49 \%)$ and $3(50-100 \%)]$. Protein expression was then defined as negative, weak (score 1-2), moderate (score 3-4) or strong (score $\geq 5$ ).

Immunohistochemical procedure. Formalin-fixed, paraffinembedded sections were de-waxed with xylene and rehydrated through gradient ethanol into phosphate-buffered solution (PBS). Endogenous peroxidase activity was quenched with $0.3 \% \mathrm{H}_{2} \mathrm{O}_{2}$ in methanol for $10 \mathrm{~min}$ at room temperature. At the same time, $2 \mathrm{ml}$ Tris-EDTA buffer (ab93684; Abcam, Cambridge, MA, USA) was added to $198 \mathrm{ml}$ of distilled water, and agitated. Prepared retrieval solution was added to the microwaveable vessel. When the time elapsed, the slides were washed in PBS three times and placed into the microwaveable vessel. The vessel was placed inside the microwave, set to full power for $10 \mathrm{~min}$, at the higher power for $5 \mathrm{~min}$ and at the medium power for $5 \mathrm{~min}$. The procedure was monitored for evaporation and watched for boiling over during the procedure in order that the slides did not dry out. When the retrieval solution evaporated during boiling, hot retrieval solution was added. When 20 min elapsed, the vessel was removed, cooled, and the slides washed in PBS three times. Protein block was applied for $5 \mathrm{~min}$ before application of the rabbit polyclonal antibody to HE4 [anti-HE4 antibody (EPR16658) (ab200828), 1:2,000 dilution]. After $2 \mathrm{~h}$ incubation with the primary antibody, the slides were washed in PBS, biotinylated goat anti rabbit IgG secondary antibody was applied and the antibody was incubated for $10 \mathrm{~min}$ at room temperature. Slides were washed three times in PBS and streptavidin peroxidase was applied for $10 \mathrm{~min}$ at room temperature. At the same time, $20 \mu l$ 3,3'-diaminobenzidine (DAB) chromogen was added to
Table I. Demographic characteristics, histological sub-types and results of immunostainings.

\begin{tabular}{lccc}
\hline $\begin{array}{l}\text { Patient } \\
\text { characteristics }\end{array}$ & $\mathrm{n}$ & $\begin{array}{c}\text { HE4 } \\
\text { negative (\%) }\end{array}$ & $\begin{array}{c}\text { HE4 } \\
\text { positive (\%) }\end{array}$ \\
\hline $\begin{array}{l}\text { Age (years) } \\
\text { Gender }\end{array}$ & $35-80$ & & \\
$\quad$ Male & 79 & $58(73.4)$ & $21(26.6)$ \\
Female & 16 & $5(31.25)$ & $11(68.75)$ \\
Histological & & & \\
subtypes & & & \\
Squamous & 29 & $26(89.65)$ & $3(10.35)$ \\
Adeno & 33 & $7(21.2)$ & $26(78.8)$ \\
Small cell & 33 & $30(90.9)$ & $3(9.01)$ \\
Total no. of patients & 95 & $63(66.3)$ & $32(33.7)$ \\
\hline
\end{tabular}

HE4, human epididymis protein 4.

$1 \mathrm{ml}$ of DAB substrate and swirled. When the time elapsed, the slides were washed in PBS three times and prepared chromogen was applied to tissues for $10 \mathrm{~min}$ at room temperature. Slides were again washed in PBS three times and lightly counterstained with hematoxylin, followed by dehydration and coverslip mounting.

\section{Results}

A low number of tumor cells was evidenced in three SCLC and six NSCLC cases and they were excluded from the study. During IHC staining, 18 SCLC and 19 NSCLC samples were washed using antigen retrieval heating. In total, 95 patients were eligible for the study. There were 79 male and 16 female patients, aged 35-80 years (mean, 61 years) (Table I).

Of the 33 SCLC cases successfully stained with HE4, there were three $2(+)$ staining (Fig. 1), whereas 30 cases $(90.1 \%$ ) were negative with HE4. The HE4 positive staining of these cases was cytoplasmic and moderate. Among the SCC cases, there were one 1(+) and two 3(+) staining. One of the 3(+) SCC staining revealed intracytoplasmic globule (Fig. 2, arrow). Additionally, the HE4 staining of AC cases was mostly diffuse, whereas it was focal in SCC cases. For the HE4-positive NSCLC cases, adenocarcinomas outnumbered (26/29 cases) the other cancer types. In particular, there were five $1(+)$, five 2(+) and sixteen 3(+) HE4-positive AC cases (Fig. 3).

\section{Discussion}

Early diagnosis to reduce the morbidity and mortality of cancer has led to a search for new, more sensitive and specific tumor markers. Of these, HE4 is a novel marker that has been investigated mostly in ovarian carcinomas (13). However, recent studies showed that it is not exclusive to ovarian carcinomas $(6,14)$.

HE4 serum levels in patients with lung carcinoma have been compared to healthy controls regarding whether it 


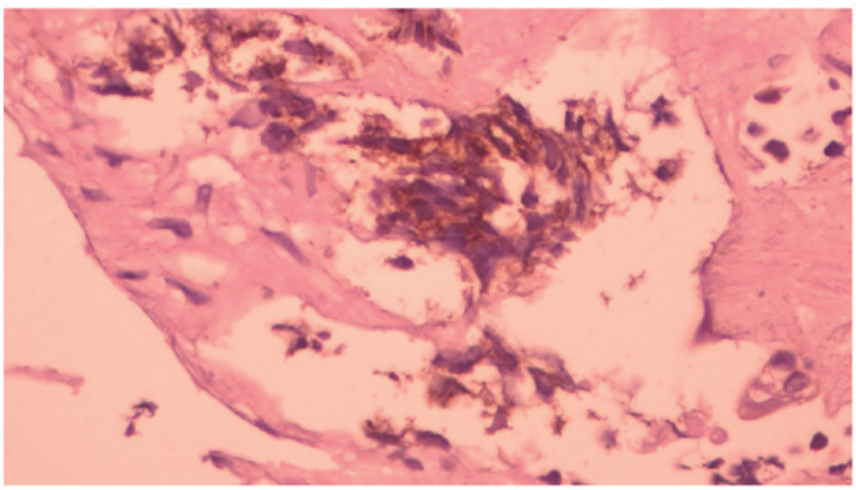

Figure 1. Scant cytoplasm is characteristic of small cell carcinoma of the lung. Note the brown color around the nuclei (magnification, $\mathrm{x} 40$ ).

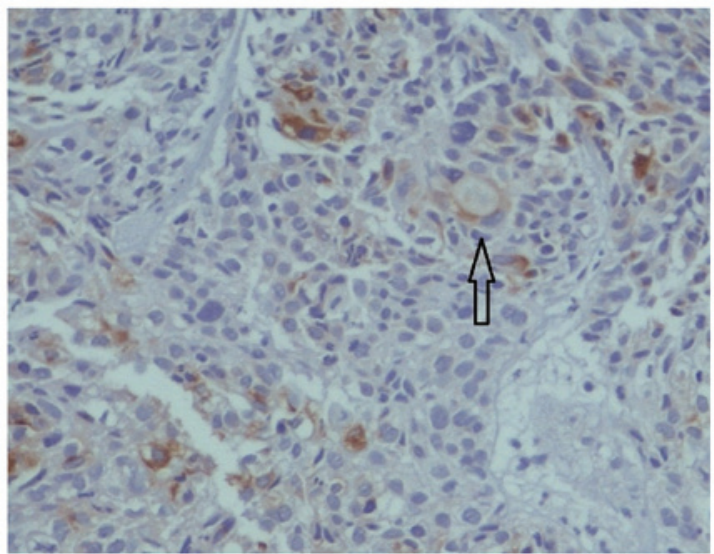

Figure 2. Squamous cell carcinoma of the lung. Arrow indicates intracytoplasmic globule which may represent combined adenocarcinoma + squamous cell carcinoma. Squamous cell carcinomas were devoid of HE4 + expression. This combined tumor explains the reason for HE4 expression in this squamous cell carcinoma (magnification, $\mathrm{x} 20$ ). HE4, human epididymis protein 4

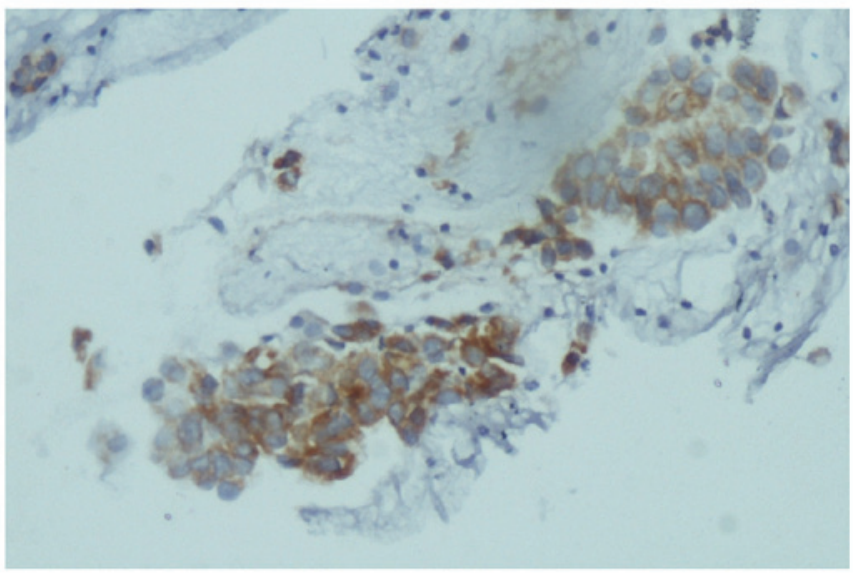

Figure 3. Strong (3+) human epididymis protein 4 (HE4) immunostaining is evident in this adenocarcinoma cases (magnification, $\mathrm{x} 10$ ).

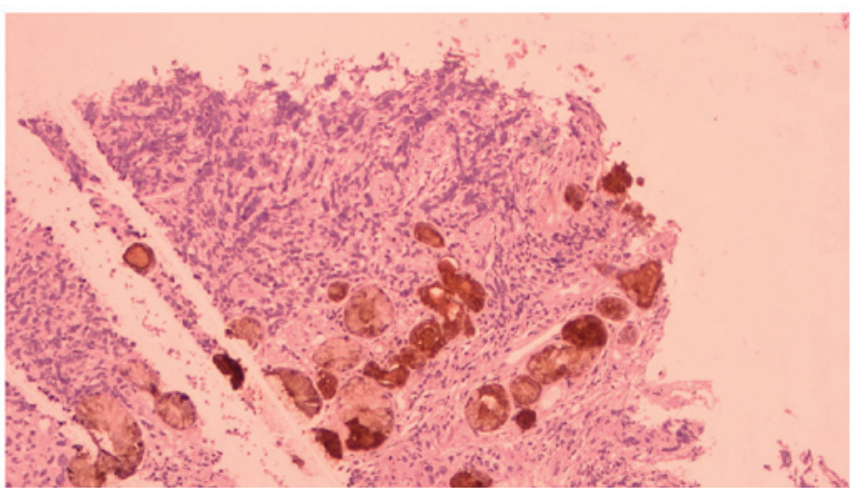

Figure 4. Blue nuclei visible in the upper part of this tissue have the characteristic crushing artefact of the tumor. Tumor is devoid of human epididymis protein 4 (HE4) expression. Note the sub-mucosal bronchial glands which reveal positive internal control (magnification, $\mathrm{x} 10$ ). identifies patients with lung carcinoma. The results obtained are promising.

Liu et al successfully distinguished lung cancer from Pulmonary Tuberculosis by measuring the serum level of HE4 (8). The area under the ROC curve (AUC) value for serum HE4 was 0.821 for differentiating lung cancer patients from healthy controls (specificity at the cutoff $89.3 \%$ ) and it went up to 0.98 for patients with AC histology (15). Nagy et al found a higher level of HE4 in all the stages of lung cancer patients, and a significant correlation between HE4 values and the tumor size determined by computed tomography was observed in their study (16).

A recent study was conducted on SCLC using HE4 assays to analyze the serum of 63 patients with SCLC, compared to 66 controls (10). The AUC for HE4 was 0.884 . Another study used the optimal cut-off value of 84.19 pmol/1 HE4 serum level and was able to distinguish SCLC patients from healthy controls with a sensitivity of $69.4 \%$ and a specificity of $93.3(7)$.

The diagnostic value is also the same for NSCLC patients. Iwahori et al (17) found elevated levels of serum HE4 not only in SCLC patients $(88.9 \%, 8 / 9$ patients) but also in NSCLC patients $(90.0 \%, 36 / 40$ patients). One significant study examined SCC and AC patients separately and found that HE4 serum levels were $125.05 \pm 89.06$ and $357.04 \pm 220.40 \mathrm{pmol} / 1$, respectively (18). Both levels were higher than that of healthy subjects (the level for healthy subjects was $29.67 \pm 5.37 \mathrm{pmol} / 1$ in this study). Follow-up of another NSCLC patients revealed that serum levels of HE4 successfully predicted tumor recurrence in early stage lung cancer (19). On the other hand, this difference was not found between AC and SCC cases in two different studies $(15,16)$.

Studies regarding the expression of HE4 have been mostly focused on the serum levels of patients. However, studies investigating HE4 expression difference between histological sub-types of lung cancer are limited. One study observed strong intracytoplasmic HE4 staining in their SCLC cases. Strong intracytoplasmic HE4 staining was also evident in our SCLC cases but the number was merely three cases. In the present study, strong staining was observed mostly in adenocarcinoma cases. Moreover, one of the two 3(+) staining observed in SCC cases had intracytoplasmic globule. In our opinion, this globule is the minor focus of the mixed tumor, i.e., the adeno component of an adenosquamous carcinoma.

The HE4 serum level of the three lung cancer subtypes, SCLC, AC and SCC cases, were examined and it was concluded that HE4 was the optimal biomarker both in AC and 
SCC (4). No difference was observed between the different histological subgroups in two different studies $(16,20)$. One of these studies examined a patient's serum prior to chemotherapy and failed to detect any association between HE4 level and histologic subtype among 153 metastatic lung cancer patients (20). Consistent with these studies, we have not observed such a higher cytoplasmic staining among our SCLC cases but HE4 expression among NSCLC cases is consistent with the literature $(9,12)$. We observed HE4 expression in the cytoplasm of bronchial glands next to tumor cells. The origin of SCLC is not the bronchial gland and SCC is thought to arise from metaplastic bronchial glands that lost the phenotype of the cell. These two explanations may explain the lower rate of HE4 expression observed in SCLC and SCC cases. However, other explanations for the elevated serum level of HE4 remain to be reported in the literature.

First of all, intracellular localization of HE4 was investigated in ovarian cancer cells (21) and HE4 colonization was observed around the Golgi complex and endoplasmic reticulum. Considering the scant cytoplasm of SCLC cells, which is devoid of organelles, non-detection of HE4 protein in SCLC cells is expected. Secondly, SCLC cells have a rapid turnover rate and the cells may be so committed to cell division that, there is no effort to produce other proteins such as HE4. Lastly, lung carcinomas are combined tumors, and two different histological types can be seen in the tumor. The frequency of SCLC/adenocarcinoma or SCLC/squamous cell carcinoma is $2-20 \%(22,23)$ and the frequency of combined tumors varies depending on the type of specimen (resection vs. small biopsy). Our cases consisted of small samples and the second component may not have been sampled. This second component of the tumor may be the source of higher serum level of HE4 in lung carcinoma in general. The retrospective nature of this study did not allow for examination of the serum level of HE4. This is a major limitation of this study.

In conclusion, HE4 is present in the cytoplasm of bronchial glands and adenocarcinoma cells but it is rarely present in small cell lung carcinoma and squamous cell carcinoma cells. The results of the present study confirmed that HE4 is a biological marker for lung cancer detection but only for combined tumors. Screening of HE4 serum level may not be a reliable marker for the detection of whole lung carcinoma patients but it is a promising candidate for adenocarcinoma treatment.

\section{Acknowledgements}

We thank Mert Cesur and Onur Ergun for their assistance in obtaining archival formalin-fixed, paraffin-embedded tissues. The authors thank Mr. David M. Silverman for his final editing. This study was funded by the Educational Commission at Antalya Training Hospital.

\section{References}

1. Kirchhoff C, Habben I, Ivell R and Krull N: A major human epididymis-specific cDNA encodes a protein with sequence homology to extracellular proteinase inhibitors. Biol Reprod 45: 350-357, 1991.

2. Ma Q, Wang Q and Zhong D: Advances of human epididymis protein 4 in lung cancer. Zhongguo Fei Ai Za Zhi 18: 184-186, 2015 (In Chinese).
3. Hua L, Liu Y, Zhen S, Wan D, Cao J and Gao X: Expression and biochemical characterization of recombinant human epididymis protein 4. Protein Expr Purif 102: 52-62, 2014.

4. Lu R, Sun X, Xiao R, Zhou L, Gao X and Guo L: Human epididymis protein 4 (HE4) plays a key role in ovarian cancer cell adhesion and motility. Biochem Biophys Res Commun 419: 274-280, 2012.

5. Bingle L, Cross SS, High AS, Wallace WA, Rassl D, Yuan G, Hellstrom I, Campos MA and Bingle CD: WFDC2 (HE4): A potential role in the innate immunity of the oral cavity and respiratory tract and the development of adenocarcinomas of the lung. Respir Res 7: 61, 2006.

6. Zeng Q, Liu M, Zhou N, Liu L and Song X: Serum human epididymis protein 4 (HE4) may be a better tumor marker in early lung cancer. Clin Chim Acta 455: 102-106, 2016.

7. Wang X, Fan Y, Wang J, Wang H and Liu W: Evaluating the expression and diagnostic value of human epididymis protein 4 (HE4) in small cell lung cancer. Tumour Biol 35: 6847-6853, 2014.

8. Liu W, Yang J, Chi PD, Zheng X, Dai SQ, Chen H, Xu BL and Liu WL: Evaluating the clinical significance of serum HE4 levels in lung cancer and pulmonary tuberculosis. Int J Tuberc Lung Dis 17: 1346-1353, 2013.

9. Yamashita S, Tokuishi K, Moroga T, Yamamoto S, Ohbo K, Miyahara S, Yoshida Y, Yanagisawa J, Hamatake D, Hiratsuka M, et al: Serum level of HE4 is closely associated with pulmonary adenocarcinoma progression. Tumour Biol 33: 2365-2370, 2012.

10. Wojcik E, Tarapacz J, Rychlik U, Stasik Z, Sas-Korczynska B, Skotnicki P and Kulpa JK: Human epididymis protein 4 (HE4) in patients with small-cell lung cancer. Clin Lab 62: 1625-1632, 2016.

11. Lan WG, Hao YZ, Xu DH, Wang P, Zhou YL and Ma LB: Serum human epididymis protein 4 is associated with the treatment response of concurrent chemoradiotherapy and prognosis in patients with locally advanced non-small cell lung cancer. Clin Transl Oncol 18: 375-380, 2016.

12. Yamashita S, Tokuishi K, Hashimoto T, Moroga T, Kamei M, Ono K, Miyawaki M, Takeno S, Chujo M, Yamamoto S, et al: Prognostic significance of HE4 expression in pulmonary adenocarcinoma. Tumour Biol 32: 265-271, 2011.

13. Bulut T, Celik B, Yalcin AD and Keser S: Tissue expression of HE4 a and its correlation with CA125 and P53 in high grade serous ovarian carcinoma. Eur J Gynaecol Oncol: doi: 10.12892/ejgo3992.2017 (Epub ahead of print).

14. Yang Z, Zhang Z, Qin B, et al: Human epididymis protein 4: A novel biomarker for lupus nephritis and chronic kidney disease in systemic lupus erythematosus. J Clin Lab Anal: 897-904, 2016. doi: $10.1002 /$ jcla.21954.

15. Yoon HI, Kwon OR, Kang KN, Shin YS, Shin HS, Yeon EH, Kwon KY, Hwang I, Jeon YK, Kim Y, et al: Diagnostic value of combining tumor and inflammatory markers in lung cancer. J Cancer Prev 21: 187-193, 2016.

16. Nagy B Jr, Bhattoa HP, Steiber Z, Csobán M, Szilasi M, Méhes G, Müller M, Lázár J, Kappelmayer J and Antal-Szalmás P: Serum human epididymis protein 4 (HE4) as a tumor marker in men with lung cancer. Clin Chem Lab Med 52: 1639-1648, 2014.

17. Iwahori K, Suzuki H, Kishi Y, Fujii Y, Uehara R, Okamoto N, Kobayashi M, Hirashima T, Kawase I and Naka T: Serum HE4 as a diagnostic and prognostic marker for lung cancer. Tumour Biol 33: 1141-1149, 2012.

18. Tang QF, Zhou ZW, Ji HB, Pan WH and Sun MZ: Value of serum marker HE4 in pulmonary carcinoma diagnosis. Int J Clin Exp Med 8: 19014-19021, 2015.

19. Huang W, Wu S, Lin Z, Chen P and Wu G: Evaluation of HE4 in the diagnosis and follow up of non-small cell lung cancers. Clin Lab 63: 461-467, 2017.

20. Lou E, Johnson M, Sima C, Gonzalez-Espinoza R, Fleisher M, Kris MG and Azzoli CG: Serum biomarkers for assessing histology and outcomes in patients with metastatic lung cancer. Cancer Biomark 14: 207-214, 2014

21. Drapkin R, von Horsten HH, Lin Y, Mok SC, Crum CP, Welch WR and Hecht JL: Human epididymis protein 4 (HE4) is a secreted glycoprotein that is overexpressed by serous and endometrioid ovarian carcinomas. Cancer Res 65: 2162-2169, 2005.

22. Mangum MD, Greco FA, Hainsworth JD, Hande KR and Johnson DH: Combined small-cell and non-small-cell lung cancer. J Clin Oncol 7: 607-612, 1989.

23. Wallace AS, Arya M, Frazier SR, Westgate S, Wang Z and Doll D: Combined small-cell lung carcinoma: An institutional experience. Thorac Cancer 5: 57-62, 2014. 